\title{
Analysis of cyclic deformation of the aortic annulus by cine-MRI
}

\author{
Yang Chul Boering*, Sebastian Gruenig, Florian Bönner, Jan Balzer, Mirja Neizel, Marc W Merx, Tobias Zeus, \\ Burkhard Sievers, Malte Kelm \\ From 16th Annual SCMR Scientific Sessions \\ San Francisco, CA, USA. 31 January - 3 February 2013
}

\section{Background}

Imaging of the aortic annulus is paramount for the success of transcatheter aortic valve implantation (TAVI) to obviate prosthesis size mismatch. The aortic annulus is a dynamic structure with alterations of its ellipsoid shape during the cardiac cycle. The objective of this study was to investigate with cine-MRI the changes of the sagittal and coronal diameter of the aortic annulus and whether the point in time of measurement is relevant for prosthesis size selection.

\section{Methods}

40 patients (17 males, $84.3 \pm 6.7$ years) with severe aortic stenosis were studied with a 1.5 Tesla MR Scanner (Achieva, Philips, The Netherlands) before TAVI. CineMRI were acquired in coronal axis and sagittal (3-chamber) view of the left ventricle and the aortic annulus diameter was measured at maximum systole and minimal diastole in each view and the mean annulus diameter was calculated for each phase. Additionally an eccentricity index (EI), the ratio of maximum and minimum diameter was calculated as a measure of circularity of the annulus.

\section{Results}

The maximum diameter of the aortic annulus was measured at systole for both sagittal (mean $23.7 \pm 1.7 \mathrm{~mm}$ ) and coronal axis (mean $25.0 \pm 1.9 \mathrm{~mm}$ ), as the minimal diameter was measured at diastole for the sagittal (mean 21.1 $\pm 1.9 \mathrm{~mm}$ ) and the coronal view (mean $23.6 \pm 2.4 \mathrm{~mm}$ ). The degree of deformation was apparently greater in the sagittal direction than in the coronal extent $(2.6 \pm 0.6 \mathrm{~mm}$ vs. $1.5 \pm 0.8 \mathrm{~mm}$, respectively, $\mathrm{p}<0.01)$. This resulted in a more circular shape of the annulus during systole, reflected by a decreased EI in comparison to diastole $(E I=1.06 \pm 04$ vs.

Cardiology, Heinrich Heine University, Duesseldorf, Germany
$E I=1.12 \pm 0.08$, respectively, $\mathrm{p}<0.01)$. Also the mean annulus diameter was calculated $2 \mathrm{~mm}$ smaller than in systole (22.33 $\pm 2.05 \mathrm{~mm}$ vs. $24.34 \pm 1.75 \mathrm{~mm})$.

\section{Conclusions}

The deformation of the annulus during the cardiac cycle, specifically in the sagittal dimension results in diameter variations of at least $2 \mathrm{~mm}$. It is reasonable that the assessment of the annulus size should be performed in systole, when the annulus is also more circular than in diastole.

\section{Funding}

No disclosures.

Published: 30 January 2013

doi:10.1186/1532-429X-15-S1-P277

Cite this article as: Boering et al: Analysis of cyclic deformation of the aortic annulus by cine-MRI. Journal of Cardiovascular Magnetic Resonance 2013 15(Suppl 1):P277.

\section{Submit your next manuscript to BioMed Central and take full advantage of: \\ - Convenient online submission \\ - Thorough peer review \\ - No space constraints or color figure charges \\ - Immediate publication on acceptance \\ - Inclusion in PubMed, CAS, Scopus and Google Scholar \\ - Research which is freely available for redistribution

(C) 2013 Boering et al; licensee BioMed Central Ltd. This is an Open Access article distributed under the terms of the Creative Commons Attribution License (http://creativecommons.org/licenses/by/2.0), which permits unrestricted use, distribution, and reproduction in any medium, provided the original work is properly cited. 